\title{
Incidence of Major Clinical Reproductive Health Problems of Dairy Cows at Bako Livestock Research Farm over a Two-Year Period (September 2008-December 2010)
}

\author{
Temesgen Ayana ${ }^{1, *}$, Tegegn Gudeta ${ }^{2}$ \\ ${ }^{1}$ Department of Veterinary Laboratory Technology, Ambo University, Ambo, Ethiopia \\ ${ }^{2}$ Max Planck Institute for Developmental Biology, Tuebingen, Germany
}

Email address:

tadefa2005@yahoo.co.uk (T. Ayana)

\section{To cite this article:}

Temesgen Ayana, Tegegn Gudeta. Incidence of Major Clinical Reproductive Health Problems of Dairy Cows at Bako Livestock Research Farm Over a Two-Year Period (September 2008-December 2010). Animal and Veterinary Sciences. Vol. 3, No. 6, 2015 , pp. 158-165.

doi: 10.11648/j.avs.20150306.13

\begin{abstract}
A prospective follow up study was carried out on 372 dairy cows at Bako Agricultural research center between September 2008 and December 2010 to determine the incidence of reproductive problems and associated risk factors in the cows. The animals were continuously followed from insemination/mating until 45 days postpartum for occurrence of clinical reproductive problems. Data were collected during farm visits by observation and clinical examination of animals. The cumulative incidence of clinically observed major reproductive problems was $35.2 \%$ (131/372). No statistically detectable effect ( $p>0.05$ ) of breed was shown on the occurrence of clinical reproductive problems evaluated. In addition, number of parities, body condition score (BCS), age of dams, calf sex and service type were not found to have a significant influence on the occurrence of reproductive problems in the study farm $(\mathrm{p}>0.05)$. The most common reproductive problems recorded in the present study were retained fetal membrane (8.3\%), dystocia (6.7\%), abortion (5.9\%), uterine infections (5.6\%) and stillbirths (4.8\%). In this study, the incidence of dystocia, uterine infections, stillbirths and repeat breeding were more common in crossbred cows whereas abortion was more common in local cows but the effect of these factors was not significant ( $\mathrm{p}>0.05)$. This study revealed that nearly one cow out of every three cows encountered at least one type of clinical reproductive problems indicating the widespread occurrence of the problems among dairy cows at Bako Agricultural Research Center. However, considered plausible factors such as breed, parity number, body condition score (BCS), age of dams, calf sex and service type had no significant influence on the occurrence of reproductive problems in the study farm indicating that some other factors are responsible for precipitating the conditions. It is, therefore, recommended that other factors that precipitate the occurrence of the problems in the farm should be investigated and appropriate interventions implemented in order to minimize the occurrence of these problems and associated losses in the farm.
\end{abstract}

Keywords: Bako, Dairy Cows, Incidence, Follow Up, Reproductive Problems, Risk Factors

\section{Introduction}

Reproductive efficiency is a critical component of a successful dairy operation and acts as an important component of a profitable dairy farm, whereas reproductive inefficiency is one of the most costly problems facing the dairy industry today. Reproductive problems occur frequently in dairy cows and can dramatically affect reproductive efficiency in a dairy herd [1]. Reproductive problems have been implicated to cause considerable economic loss to the dairy industry due to slower uterine involution, reduced reproductive rate, prolonged inter-conception period and calving interval, high cost of medication, drop in milk production, reduced calf-crop and early depreciation of potentially useful cows $[2,3]$. Low reproductive efficiency also hinders genetic improvement in Zebu (Bos indicus) cattle and causes a direct economic loss [4]. In addition, several studies have shown that reproductive disorders are the most frequent culling reasons $[5,6,7]$.

Among the most common reproductive disorders that have direct impact on reproductive performance of dairy cows include, twinning, dystocia, abortion, retained fetal membrane, stillbirth and metritis. These are diverse disorders that are similar in that they all can result in impaired 
reproductive function. Deciding whether to breed, treat, or cull dairy cows exhibiting one or more of these reproductive problems is a challenge for both veterinarians and dairy producers [1].

Bako Agricultural Research center is one of the leading public dairy research centers in Ethiopia that is engaged in dairy development research endeavor for more than five decades. The center has played a significant role in adopting and generating appropriate technologies and promoting the transfer of improved dairy technologies to smallholder farmers for dairy development in the country $[8,9]$. However, limited effort has been made to assess the conditions of reproductive problems of dairy cows under on-station condition [10]. In addition, the effect of reproductive disorders on reproductive performance of dairy cattle has not been sufficiently studied. This study was, therefore, designed to determine the incidence of periparturient reproductive conditions and associated factors in both local Zebu and crossbred dairy cows under on-station condition.

\section{Materials and Methods}

\subsection{Study Area}

The study was carried out at Bako Agricultural Research Center between September 2008 and December 2010. The center is located at $260 \mathrm{~km}$ west of Addis Ababa in East Wollega Zone of Oromia National Regional State, Ethiopia. It lies between $9^{\circ} 6^{\prime} \mathrm{N}$ latitude and $37^{\circ} 09^{\prime} \mathrm{E}$ longitude and has an altitude of 1650 meter above sea level (masl). The longterm weather information collected at the center reveals that the area gets a bimodal pattern of rainfall with the main rainy season extending from June to September and a short rainy season that extends from March to May with an average annual rainfall of $1300 \mathrm{~mm}$. The area has sub-humid agroecology. The mean minimum, mean maximum and average air temperatures were $14.1,27.9$ and $20.6{ }^{\circ} \mathrm{C}$, respectively [11]. Majority of soil in western Oromia (Ethiopia) in general and the study site in particular are Nitosols or Alifisols according to USDA soil classification systems [12]. The topography of the area ranges from gently undulating to dissected hills and its geology is characterized by Tertiary and Quaternary age rhyolite and basalt volcanics [13]. The soil is deep and highly weathered, well drained, clay texture and slightly acidic in reaction [14]. Semi-deciduous primary natural vegetation and grassland surround the research center. Maize (Zea mays), sorghum (Sorghum bicolor), teff (Eragrostis tef), hot pepper (Capsicum frutescence), sweet potato (Ipomoea batatas), haricot bean (Phaseolus vulgaris), mango (Mangifera indica), banana (Musa spp.) and sugar cane (Saccharum officinarum) are the major annual and perennial crops grown in the study area. Dominant grasses species include Hyperhenia and Sporobolus [15].

\subsection{Animals and Their Management}

The livestock farm of the center is mandated to evaluate the growth, productive and reproductive performances of the indigenous Horro cattle breed and their crosses with various exotic bloods [15]. The study animals, aged between 3 to 16 years, were of varying parities, body condition scores, and breeds. Breeds of the animals were identified from the existing records. The proportion of exotic blood in crossbred animals ranged from $50 \%$ to $62.5 \%$. Horro cattle (zebu that are reared in the area) has traditionally been used for draft power, milk and meat production in low-input production systems. The breed is classified as an intermediate (SangaZebu) with fine skin and uniform brown color which is lighter around the muzzle and on the flanks, abdominal floor and perineum and in between the hind legs [16].

The study animals were managed by semi-intensive production system. The animals were housed (in herds) in a barn with concrete floor and corrugated iron roof. Pregnant cows and heifers were separated into maternity pens during night. The feeding system of heifers and cows of all breeds were similar. All animals above 6 months of age were let in a group to graze natural pasture ( 8 am to $5 \mathrm{pm}$ ). Concentrate supplement was restricted to calves, milking cows and pregnant cows (mainly during the last trimester of pregnancy). The concentrate mixture included maize (49.5\%), Noug seed cake (49.5\%), and salt (1\%). Supplementation with hay (Rhodes grass/Chloris gayana and natural pasture) or silage (Rhodes grass and maize silage) at night was practiced depending on the availability of hay and silage and the condition of the grazing paddocks. All animals were routinely monitored for any health problem and those above six months of age were annually vaccinated against Black leg, Anthrax, Bovine Pasteurellosis, Lumpy Skin Disease (LSD) and Foot and Mouth disease (FMD). All the animals were de-wormed with anthelmintics twice a year; during the beginning of the main rainy season and end of the main rainy season. The animals were sprayed with acaricide (Diazinon 60\% EC) against external parasites; the frequency of spray varies depending on the degree of infestation and season of the year [17].

Heat detection was based on daily visual observation (6-8 am and 5-6 pm) by a trained inseminator and throughout the grazing time by the herdsmen. Cows and heifers observed in heat were bred either naturally (local or crossbred bull) or inseminated either with frozen Friesian, or Jersey semen obtained from National Artificial Insemination Center. Those animals that were bred and hence, not returned to estrus were checked for pregnancy using rectal palpation after two months. Postpartum breeding took place after 45 days of voluntary waiting period [15].

\subsection{Study Design}

A longitudinal study design was used to estimate incidence of reproductive health problems in dairy cows kept at Bako livestock research farm. A total of 372 pregnant dairy cows were continuously followed for occurrence of major reproductive health problems for two consecutive years. Individual cows were followed from insemination/mating until 45 days postpartum. Clinical 
examination of the reproductive system was regularly carried out to determine the nature of vaginal discharge during the postpartum period. The vulva and perineal area were inspected for the presence of any afterbirth (RFM) if not expelled out with in the first 12 hours [2] and for the presence of any discharge.

\subsection{Data Collection}

Baseline herd data were collected through direct observation and administration of self administered semistructured questionnaire. During the initial and subsequent visits, detailed data about the individual cow/heifer participating in the study were collected using a clinical record form. Farm record books were used to collect data on animal identification, age, parity, breed, and others. Monthly visits were carried out for pregnant animals that had not entered the peri-parturient period (more than three weeks prior to parturition) and weekly visits were carried out as soon as the animals entered the peri-parturient period (3 weeks before and after parturition). Data on service type, date of insemination, sex of offspring, reproductive health problems, including but not limited to dystocia (difficult calving requiring considerable assistance), stillbirth (calf born dead at term), abortion (expulsion of the fetus before the end of pregnancy), retained fetal membrane (retained longer than 12 hours after calving), prolapse (vaginal and/or uterine), uterine infections (metritis, endometritis, pyometra or uterine discharge), repeat breeder (cows requiring three or more services before conception or culling) [18, 19] were recorded from the study cows followed during the study period. Body condition of the study animals was scored based on the criteria set by Richard [20] with minor modifications to condense body conditions scores into three groups (poor, medium and good).

\subsection{Data Management and Analysis}

The collected data were entered and stored in Microsoft Office Excel 2007 (Microsoft Corporation, USA) and EpiData (EpiData version 3.1, The EpiData Association, Odense, Denmark). Reproductive conditions were recorded as binary variables ( $1=$ presence; $0=$ absence), screened for errors and exported into SPSS for Windows (Version 20.0; Statistical Package for Social Sciences Inc, Chicago, Illinois, USA) for analysis. Descriptive statistics such as mean and proportions were used to express the characteristics of different independent variables. Incidence rate was used as a measure of occurrence of reproductive problems per 100 cows calved [21]. Proportional morbidity rates (PMR) were calculated by dividing the number of cases of each reproductive problem by the total number of cases. For the purpose of analysis, crosses of local Horro with Friesian or Jersey, were combined to a single group and described as 'crossbred.' The chi-square $\left(\chi^{2}\right)$ statistic was used to determine the associations between predictor variables and incidence of reproductive problems [22]. Logistic regression was employed to check the influence of the independent variables on the dependent variable. In all the analysis, $p>0.05$ was considered to have a significant effect.

\section{Results}

The mean and standard error of the mean age and parity of the study animals were $7.30 \pm 0.17($ mean \pm SE, $7.30 \pm 0.17)$ and $4.87 \pm 0.16($ mean $\pm \mathrm{SE}, 4.87 \pm 0.16)$, respectively. In the present study, the cumulative incidence of clinically observed major reproductive problems related to the 372 cows (Local zebu=313 crossbred $=59)$ was $35.2 \% \quad(131 / 372)$. The cumulative incidence of major reproductive problems among the two genotypes were $34.2 \%$ (107/313) and 40.7\% (24/59), respectively for local Horro and crossbred animals and the incidence between the two genotypes did not differ significantly $\left(\chi^{2}=0.65, \mathrm{p}>0.05\right)$ (Table 1$)$.

Despite lack of effect of parity on incidence of reproductive disorders $\left(\chi^{2}=0.74, p>0.05\right)$, the problems were more common among single parities $(38.5 \%)$ than multiple parities (33.8\%) (Table 1). In addition, the incidence of reproductive problems were also assessed in relation to body condition score of the study cows and statistically insignificant associations $\left(\chi^{2}=1.76, p=0.41\right)$ were found. However, incidence was high in animals with poor conditions $(44.7 \%)$ than good ones $(35.4 \%)$. On the other hand, the incidence of clinical reproductive problems were higher in cows that were bred by artificial insemination than those that were bred by natural service and those that gave birth to male calves relative to those that gave birth to female calves though the differences were insignificant in both cases. Moreover, factors such as calf sex, dam age and service type did not significantly influence $(\mathrm{p}>0.05)$ the occurrence of reproductive problems (Table 1$)$.

Table 1. Bivariate associations of potential host risk factors with incidence of major clinical reproductive problems in local and crossbred dairy cows at Bako, Western Oromia, Ethiopia.

\begin{tabular}{|c|c|c|c|c|c|}
\hline Factors & Factor categories & No. of observations & No. affected (\%) & $\chi^{2}$ & p-value \\
\hline \multirow[t]{2}{*}{ Breed } & Local Horro & 313 & $107(34.2)$ & 0.655 & $0.418^{*}$ \\
\hline & Crossbred & 59 & $24(40.7)$ & & \\
\hline \multirow[t]{2}{*}{ Parity } & Primiparous & 109 & $42(38.5)$ & 0.552 & $0.457^{*}$ \\
\hline & Pluriparous & 263 & $89(33.8)$ & & \\
\hline \multirow[t]{3}{*}{ Body condition score } & Good & 79 & $28(35.4)$ & 1.760 & $0.415^{*}$ \\
\hline & Medium & 255 & $86(33.7)$ & & \\
\hline & Poor & 38 & $17(44.7)$ & & \\
\hline Age of dam (years) & $3-5$ & 127 & $49(38.6)$ & 2.479 & $0.290^{*}$ \\
\hline
\end{tabular}




\begin{tabular}{|c|c|c|c|c|c|}
\hline Factors & Factor categories & No. of observations & No. affected (\%) & $\chi^{2}$ & p-value \\
\hline & $6-10$ & 171 & $53(31.0)$ & & \\
\hline & $>10$ & 74 & $29(39.2)$ & & \\
\hline \multirow[t]{2}{*}{ Calf sex } & Male & 165 & $66(40.0)$ & 2.719 & $0.099^{*}$ \\
\hline & Female & 202 & $63(31.2)$ & & \\
\hline \multirow[t]{2}{*}{ Service type } & AI & 314 & $113(36.0)$ & 0.332 & $0.565^{*}$ \\
\hline & Bull service & 58 & $18(31.0 \%)$ & & \\
\hline
\end{tabular}

*: Not significant; AI: artificial insemination

The major types of reproductive problems recorded in the present study were retained fetal membranes $(8.3 \%, \mathrm{n}=31)$, dystocia $(6.7 \%, \mathrm{n}=25)$, abortions $(5.9 \%, \mathrm{n}=22)$, uterine infections $(5.6 \%, n=21)$ and stillbirths $(4.8 \%, n=18)$ (Fig. 1).

The incidence of major reproductive problems among local Horro and crossbred cows are given in Figure 2. The incidence of the problems didn't differ significantly between the genotypes $(p>0.05)$. In this study, the incidence of dystocia, uterine infections, stillbirths and repeat breeding were more common in crossbred cows while abortion was more frequent in local cows.

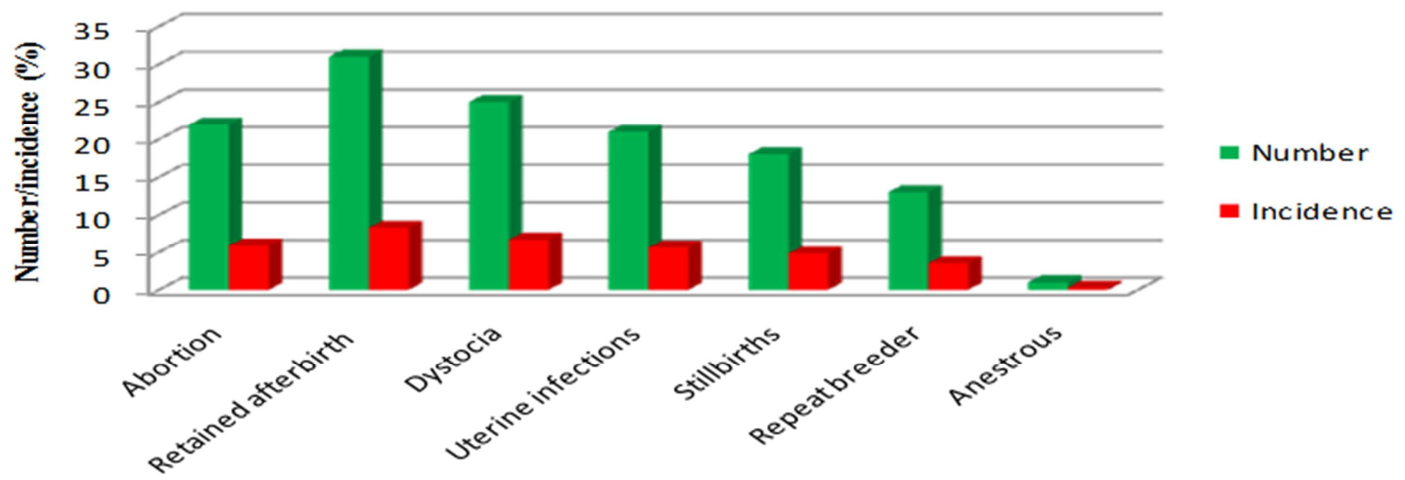

Figure 1. Number, incidence and types of clinical reproductive problems of dairy cows at Bako livestock research farm, Western Oromia, Ethiopia.

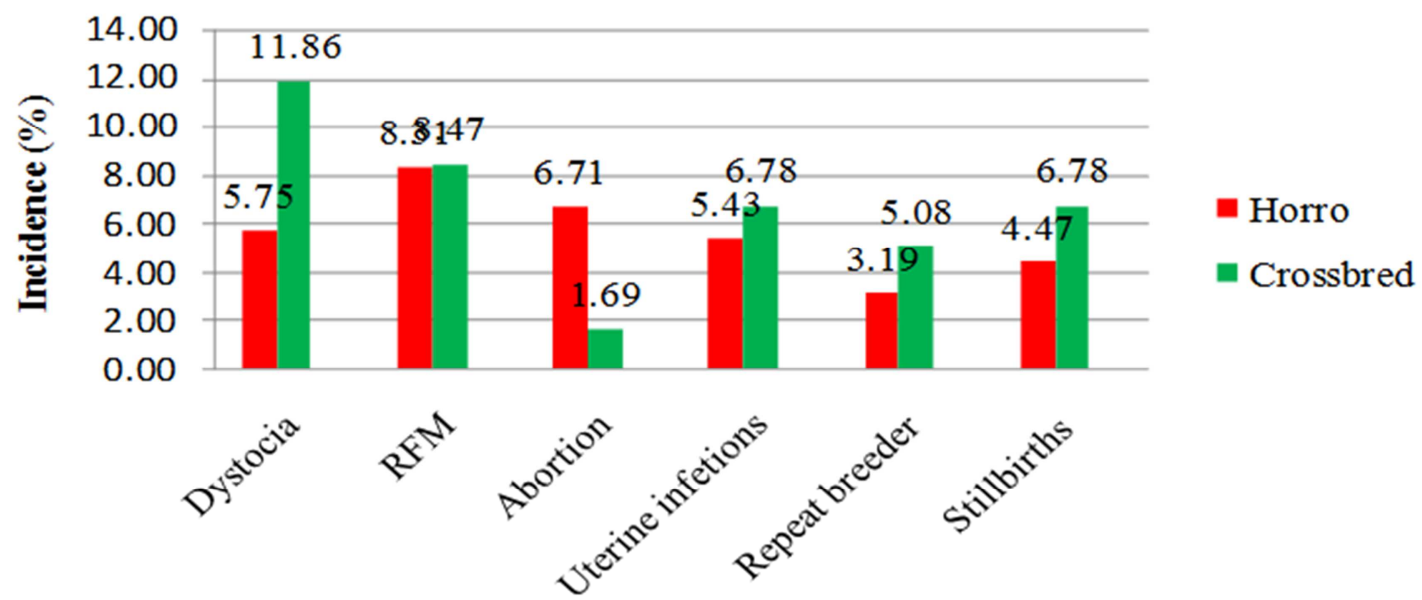

Figure 2. Incidence of major clinical reproductive problems by breed of cows at Bako Agricultural research center, Western Oromia, Ethiopia.

In this study, the overall incidence of abortion was found to be $5.9 \%$, the incidence in local Horro and crossbred cows being $7.0 \%$ and $2.0 \%$, respectively. Abortion incidence in relation to breed of study cows was also assessed and found to be statistically insignificant ( $p>0.05$ ). In our study, most of the abortions occurred in the second and third trimester of pregnancy. On the other hand, the incidence of RFM in local and crossbred dairy cows was $8.31 \%$ and $8.47 \%$, respectively, showing no effect of breed. Table 2 shows the relative frequency and incidence of RFM in cows when the data is explored further based on calf sex in both breeds of cows. Higher incidence of dystocia was observed in crossbred cows $(11.86 \%)$ than in local cows $(5.75 \%)$ though no statistically significant association was detected.

Table 2. Relative frequency and proportion of retained fetal membranes (RFM) by breed and calf sex.

\begin{tabular}{lllll}
\hline $\begin{array}{l}\text { Breed of } \\
\text { dam }\end{array}$ & Calf sex & $\begin{array}{l}\text { Total number } \\
\text { of calvings }\end{array}$ & $\begin{array}{l}\text { No. of } \\
\text { cases }\end{array}$ & $\begin{array}{l}\text { Incidence } \\
\text { (\%) of cases }\end{array}$ \\
\hline Local Horro & Male & 133 & 12 & 9.0 \\
& Female & 180 & 14 & 7.7 \\
Crossbred & Male & 34 & 2 & 5.8 \\
& Female & 25 & 3 & 12.0 \\
\hline
\end{tabular}


The incidence and proportional morbidity rate of clinically observed major reproductive problems in the present study was given in the table below (Table 3 ).

Table 3. The incidence and proportional morbidity rates (PMR) of major reproductive health problems of dairy cows at Bako between October 2008 and January 2010.

\begin{tabular}{llll}
\hline $\begin{array}{l}\text { Type of reproductive } \\
\text { problems }\end{array}$ & No. of cases & Incidence (\%) & PMR \\
\hline RFM & 31 & $8.3 \%$ & 23.66 \\
Dystocia & 25 & $6.7 \%$ & 19.08 \\
Abortion & 22 & $5.9 \%$ & 16.79 \\
Stillbirths & 18 & $4.8 \%$, & 13.74 \\
Endometritis & 15 & $4.0 \%$ & 11.45 \\
Repeat breeder & 13 & $3.5 \%$ & 9.92 \\
Pyometra & 6 & $1.6 \%$ & 4.58 \\
Anestrous & 1 & $0.3 \%$ & 0.76 \\
\hline
\end{tabular}

\section{Discussions}

In this study, the cumulative incidence of major reproductive problems of dairy cows was $35.2 \%$. This means nearly one cow out of every three cows, regardless of various host related differences, encountered at least one of the described reproductive problems during the study period. This finding fairly agrees with previous reports from different regions of Ethiopia [10, 23, 24, 25, 26, 27]. However, much higher incidences were also reported from Ethiopia [28, 29]. On the other hand, our finding is higher than previous reports from Bedelle [30] and Asella [31] in Ethiopia. These variations could arise due to differences in management, breeds of the animals, and environmental factors. Differences in management systems and environmental conditions under which cattle are maintained could greatly affect the incidence of reproductive health problems [23, 32].

In the present study, no statistically detectable effect $(p>0.05)$ of breed was shown on the cumulative incidence of major reproductive health problems evaluated. However, the incidence of the problem was higher in crossbred cows $(40.7 \%)$ than in indigenous cows $(34.2 \%)$. Consistent with our finding, other researchers [24, 33] did not detect the effect of breed on incidence of reproductive health problems in dairy cows in Ethiopia. Conversely, the lack of detectable effect of genotype on incidence of reproductive problems in our study is in disagreement with the previous reports from Ethiopia [4, 23, 25, 34]. Though our analysis could not detect significant effect of breed on occurrence of reproductive health problems, the higher incidence of the problems in crossbred cows could still suggest increased susceptibility of the animals to reproductive problems than local animals. The incidences of all the reproductive conditions assessed in this study were more common in crossbred cows than local cows. It is widely accepted that crossbred cows are less adaptive to tropical conditions such as high temperature, humidity and various diseases [4] which are typical characteristics of Bako and its surroundings. Though crossbred dairy cows require more intensive management, feeding and better health care than the indigenous zebu to attain better reproduction and production performances in the tropics [35], both the crossbred and local cows in the present study were managed under a similar management system.

The incidence of reproductive disorders among single parity and multiple parities were $38.5 \%$ and $33.8 \%$, respectively and parity had no significant effect $(\mathrm{p}>0.05)$ on the incidence of the problems. This finding is in agreement with previous works in Ethiopia [24, 29] who did not detect the influence of parity on the incidence of reproductive problems in dairy cows. In contrast to this, other researchers $[10,23,25]$ reported the effect of parity on occurrence of reproductive problems in dairy cows in Ethiopia. The effects of parity might be due to factors affecting reproduction in cows of greater parity. Aging cows and their reproductive systems probably involves more complex and permanent uterine changes than those cows with lower parities. Furthermore, an increase in parity not only brings reproductive problems but can also lead to serious locomotive, mammary and metabolic disorders [36]. The lack of influence of parity on incidence of reproductive health problems in our study could be due to, but not limited to, the much broader classification of parity category into primiparous $(109,29.3 \%)$ and pluriparous $(263,70.69 \%)$. The incidence of clinical reproductive problems were higher in cows that were bred by artificial insemination than those that were bred by natural service and those that gave birth to male calves relative to those that gave birth to female calves, though the differences were not significant $(p>0.05)$. This could have been due to the larger calf sizes in both instances which predisposed the dams to developing the problems. Even though body condition score of the study animals did not influence the incidence of reproductive health problems in the present study, incidence was high in cows with poor body conditions $(44.7 \%)$ than good $(35.4 \%)$ ones. Other host related factors such as calf sex, age of dams and service type did not significantly influence $(p>0.05)$ the incidence of reproductive problems in the present study.

The major types of reproductive health problems recorded in the present study were RFM, dystocia, abortions, uterine infections and stillbirths. In a similar fashion, several researchers $[10,23,24,25,27,28,29,33,41]$ reported a closely similar results from different dairy farms in Ethiopia. In addition, a recent review paper [1] found that RFM, dystocia, abortion, stillbirth and twinning are the main reproductive and health problems affecting dairy cows worldwide.

The incidence of RFM in our study was $8.3 \%$. Globally, the incidence varies from study to study but tends to be about $5-10 \%$ [1]. Our finding is in fair agreement with previous reports from Ethiopia [10, 25, 27, 30, 33] and elsewhere [37, $38,39]$. In contrast to our finding, higher incidences of RFM were reported from different farms in Ethiopia [23, 24, 28, $29,40,41]$. In problem herds, the incidence may be much higher. The low incidence of RFM might be linked to the low incidence of abortion (5.9\%), a known predisposing factor for RFM [42]. Other factors such as year of calving, season 
of calving, parity of dam, calf mortality, calving difficulty and fetal presentation have all been shown to affect the incidence of RFM [43].

In the present study, the incidence of dystocia of $6.7 \%$ is in agreement with previous reports [25, 28, 30, 33], but lower than the report of [44] from Ethiopia. Because definitions of dystocia vary in the literature, there is variation in the international incidence of calving difficulty. Internationally, reported incidence in dairy cattle of severe or considerable difficulty in calving varies from just below $2 \%$ to over $22 \%$. However, assistance at calving (including lower degrees of difficulties) is much more prevalent, varying from $10 \%$ to over half of the calvings [19]. Higher incidence of dystocia was observed in crossbred cows $(11.86 \%)$ than in local cows $(5.75 \%)$ though no statistically detectable association ( $>00.05$ ) was found.

On the other hand, the present study revealed the occurrence of abortion in dairy cows to be $5.9 \%$. This finding is slightly higher than the manageable limit, given the suggested target of $5 \%$ for dairy cattle [45]. Various researchers [10, 26, 28, 29, $44,31]$ reported a closely similar findings from different areas of Ethiopia. Lower incidences of $1 \%$ and $2.6 \%$ were also reported from Jimma [24] and Hosanna [33] towns in Ethiopia. Conversely, widespread cases of abortion ranging from $12.5 \%$ to even $50 \%$ were also reported from both smallholder and large dairy farms in Ethiopia [27, 30, 34]. Most of the abortions encountered in the present study were late term which could have significant consequence on the effort to get replacement heifers and stock.

The incidence of repeat breeders in the present study was $3.5 \%$. This finding is consistent with the report from Holetta town in Ethiopia [46], though both higher and lower incidences were also reported previously by different researchers from Ethiopia. Accordingly, higher incidence of repeat breeders were reported from different areas of Ethiopia $[10,26,33,44]$ and incidence as low as $0 \%$ was reported after regular follow up of pregnant dairy cows during peri-parturient period in Borena Zone of Ethiopia [27]. The difference in incidence of repeat breeders could partly be attributed to the difference in management of study animals. Majority of the higher incidences of repeat breeders reported above were based on dairy animals managed under extensive production in which cows in heat may not be properly followed and inseminated accordingly. In addition, lower incidence of repeat breeding in our study could be due to better follow-up of cows in heat for insemination and better technical efficiency of the inseminator. The incidence of stillbirths in this study of $4.8 \%$ was similar to other studies that had reported incidence ranging from $2.8 \%$ to $10 \%[1,25$, $28,47,48]$.

\section{Conclusions}

This study revealed the high incidence of major clinical reproductive problems in study animals. The most common type reproductive problems were retained fetal membrane, dystocia, abortion, uterine infections and stillbirths. This study revealed that nearly one cow out of every three cows encountered at least one type of clinical reproductive problems indicating the widespread occurrence of the problems among dairy cows kept on station at Bako Agricultural Research Center. However, considered plausible factors such as breed, parity number, body condition score (BCS), age of dams, calf sex and service type were had no significant influence on the occurrence of reproductive problems in the study farm indicating that some other factors are responsible for precipitating the conditions. It is, therefore, recommended that other factors that may precipitate the occurrence of the problems in the study animals should be identified and prevented to minimize the occurrence of these problems and associated losses not only to the center but also to the far demanding smallholder farmers in the area who hugely depend on the center for crossbred heifers.

\section{Acknowledgements}

The study was based on data collected from dairy cows at Bako Agricultural Research Center, the center to which the authors were affiliated. Thus, we, the authors would like to express our gratitude to the centre for allowing us to collect the data from the animals and the staff members of the dairy research team of the center who have been involved in data collection.

\section{References}

[1] Ghavi Hossein-Zadeh, N. (2013). Effects of main reproductive and health problems on the performance of dairy cows: a review. Span. J. Agric. Res. 11(3): 718-735.

[2] Bekana, M., Ekman, T. and Kindhal, H. (1994a). Ultrasonography of Bovine postpartum cows with retained fetal membranes. J. Vet. Med. A. 41: 653-662.

[3] Bekana, M., Jonsson, P., Kindhal, H. (1997). Bacterial isolates with retained fetal membranes and subsequent ovarian activity in cattle. Vet. Rec., 140: 232-234.

[4] Mukasa-Mugerwa, E., Azage, T., Tafese, M. and Teklu, Y. (1991).Reproductive efficiency of Bos indicus (Zebu) cows under artificial insemination. Anim. Reprod. Sci., 24: 63-72.

[5] Esslemont RJ, Kossaibati, MA. (1997). Culling in 50 dairy herds in England. Vet. Rec. 140: 36-39.

[6] Seegers, H., Beaudeau, F., Flourichon, C. and Bareille, N. (1998). Reasons for culling in French Holstein cows. Prev. Vet. Med. 36: 257-271.

[7] Stevenson, MA. and Lean, IJ. (1998). Descriptive epidemiological study on culling and deaths in eight dairy herds. Australian Vet. J. 76: 482-488.

[8] Asfaw, C., Gebreyohanes, G., Kebede, G., Kebede, K. and Tola, A. (2000). Reproductive performance and lactation yield of $\mathrm{F} 1$ (Bos indicus $\mathrm{x}$ Bos Taurus) animals at Bako. In: Proceedings of 7 th Annual Conference of the Ethiopian Society of Animal Production (ESAP), held in Addis Ababa, Ethiopia, 26-27 May 1999: 386-396. 
[9] Gebreyohannes, G. and Kebede, M. (2006). Herd life and lifetime calf crop production in relation to age at first calving in indigenous and crossbred cows at Bako, Ethiopia. Eth. J. Anim. Prod. 6(1): 55-65.

[10] Haftu, B. and Gashaw, A. (2009). Major Reproductive Health Problems of Dairy Cows in and around Bako, West Ethiopia. Eth. J. Anim. Prod. 9(1): 89-98.

[11] Kebede, M., Greyling, JPC., Schwalbach LMJ. and Duguma, G. (2006). Effect of season and supplementation on semen and testicular characteristics of Horro bulls in sub-humid environmental condition in Ethiopia. Eth. J. Anim. Prod. 6(1): 19-32.

[12] Fikru, A. (1988). Need for soil survey studies. pp. 15-20. In: Desta Beyene (ed.). Proceedings of soil science research review in Ethiopia. Institute of Agricultural Research (IAR), 11-14 February 1986, Addis Ababa, Ethiopia.

[13] Anon (1996). Omo-Gibe River Basin Integrated Development Master Plan Study. Final Report. Vol. Vll. Land Resource Survey. B1. Federal Democratic Republic of Ethiopia. Ministry of Water Resources. Richard Woodroofe and Associates with Marcott, UK. 202.

[14] Sahlemedhin, S. and Ahmed, A. (1983). Phosphorus sorption characteristics of some Ethiopian soils. Eth. J. Agri. Sci. 5: 112.

[15] Gebreyohannes, G., Tegegne, A., Diedhiou, ML. and Hegde, BP. (2003). Reproduction efficiency of zebu and crossbred cows as measured by the inter-estrus and inter-service intervals at Bako. Proceedings of the 10th annual conference of the Ethiopian Society of Animal Production (ESAP) held in Addis Ababa, Ethiopia, August 21-23, Addis Ababa, Ethiopia.

[16] Alberro, M., and Hailemariam, S. (1982). The indigenous cattle of Ethiopia, Part I. World Anim. Rev. 41: 2-11.

[17] Ayana, T., Tafess, K., Mamo, G., Sisay, T. and Ameni, G. (2013). Isolation and molecular characterization of nontuberculosis mycobacteria from skin positive reactors and pathological lesions of cattle at Bako, Western Ethiopia. Afr. J. Microbiol. Res. 7(20): 2190-2197.

[18] Peter, AT. (2000). Abortions in dairy cows: New insights and economic impact. Adv. Dairy Technol. 12: 233-244.

[19] Mee, JF. (2008a). Prevalence and risk factors for dystocia in dairy cattle: a review. Vet. J. 176(1): 93-101.

[20] Richard, W. (1993). Dairying. Tropical Agriculturalist, 1st ed. Macmillan Press London. 43-48.

[21] Kelton, DF., Lissemore, KD. and Martin, ER. (1998). Recommendations for recording and calculating the incidence of selected clinical diseases of dairy cattle. J. Dairy Sci. 81: 2502-2509.

[22] Clark, GM. (1982). Statistics and experimental design. A series of student text in contemporary biology. 2nd ed. Edward Arnold, London. 48-62.

[23] Gizaw, M., Bekana, M., Abayneh, T. (2007). Major reproductive health problems in smallholder dairy production in and around Nazareth town, Central Ethiopia. Vet. Online Int. J. Vet. http://www.fourmilab.ch/rpkp/experiments/analysis.

[24] Gashaw, A., Worku, F. and Mulugeta, S. (2011). Assessment of smallholder dairy production and their reproductive health problems in Jimma Town, South-Western Ethiopia. Int. J. App. Res. 9: 80-86.

[25] Tesfaye, D. and Shamble, A. (2013). Reproductive health problems of cows under different management systems in Kombolcha, Northeast Ethiopia. Adv. Biolo. Res. 7 (3): 104108, 2013.

[26] Esheti, G. and Moges, N. (2014). Major Reproductive Health Disorders in Cross Breed Dairy Cows in Ada'a District, East Shoa, Ethiopia. Global Veterinaria. 13 (4): 444-449.

[27] Benti, D. and Zewdie, W. (2014). Major reproductive health problems of indigenous Borena cows in Ethiopia. J. Adv. Vet. Anim. Res. 1(4): 182-188.

[28] Kassa, T. and Lema, M. (2005). Study on major reproductive problems of Zebu and Friesian x Zebu crossbred cows under small-scale dairy farms in Ada'a District, Oromia, Ethiopia. Eth. Vet. J. 9 (1): 109-122.

[29] Haile, A., Kassa, T., Mihret, M. and Asfaw, Y. (2010). Major reproductive disorders in cross breed dairy cow under smallholding in Addis Ababa milk shed. World J. Agri. Sci. 6(4): 412-418.

[30] Bitew, M. and Prased, S. (2011). Study on Major Reproductive Health Problems in Indigenous and Cross Breed Cows in and around Bedelle, South West Ethiopia. J. Anim. Vet. Adv. 10(6):723-727.

[31] Dinka, H. (2013). Major reproductive disorders of dairy cows in and around Asella town, Central Ethiopia. J. Vet. Med. Anim. Health. 5(4): 113-117.

[32] Mureda, E. and Mekuriaw, Z. (2008). Characteristics and constraints of crossbred dairy cattle production in lowland areas of Eastern Ethiopia. Live. Res. Rural Dev. 20(4).

[33] Haile, A., Tsegaye, Y. and Tesfaye, N. (2014). Assessment of Major Reproductive Disorders of Dairy Cattle in Urban and Per Urban Area of Hosanna, Southern Ethiopia. Anim. Vet. Sc. 2(5): 135-141.

[34] Tekelye, B., Kasali, OB. and Tsion, A. (1991). Reproductive problems in crossbred cattle in central Ethiopia. Anim. Reprod. Sci. 26: 41-49.

[35] Fielding and Matthewman (2004). Tropical cattle management In: Bovine medicine, diseases and husbandry of cattle. 2nd ed. (editors. Andrews AH, Blowey RW, Boyd H, and Eddy RG), Blackwell publishing company, Oxford, UK. 68-81.

[36] Hebert, AB., Bouchard, E., Dutremblay D. and Lefebure, R. (2011). Effects of reproductive disorder and parity on repeat breeder status and culling of dairy cows. Canad. J. Vet. Res. 75(2): 147-151.

[37] Erb, HW. and Martin, SW. (1980). Interrelationship between production and reproductive disease in Holstein cows. J. Diary. Sci. 63: 1911-1917.

[38] Gaines, JD. (1989). The role of record analysis in evaluating sub fertile dairy herds. Vet. Med. 84: 532-543.

[39] Correa, MT., Curtis, CR., Erb, H. N., Screlett, JM. and Smith, RD. (1990). An ecological risk factor for postpartum disorders of Holstein-Friesian cows form thirty-two New York farms. J. Dairy Sci. 73: 1515-1524. 
[40] Mamo, T. (2004). Study on major postpartum reproductive problems of smallholder dairy cows in and around Debre Zeit. DVM Thesis, AAU, Ethiopia.

[41] Lemma, A. and Kebede, S. (2011). The effect of mating system and herd size on reproductive performance of dairy cows in market oriented urban dairy farms in and around Addis Ababa. Revue Méd. Vét. 162(11): 526-530.

[42] Arthur, GH., Noakes DE., Parkinson TJ. and England, GCW. (2001). Arthur's Veterinary Reproduction and Obstetrics. 8th ed. WB Saunders Ltd., Philadelphia. 864.

[43] Mee, JF. (1991). The incidence of retained fetal membranes on nine dairy research farms over a ten-year period (1978-1987). Irish Vet. J. 44: 48-52.

[44] Birhanu, A., Harlow, CR., Gidey, G., Tadesse, D., Desta, G., Gugssa, T., and Riley, S. (2015). Assessment of reproductive performance and problems in crossbred (Holstein Friesian X
Zebu) dairy cattle in and around Mekelle, Tigray, Ethiopia. Anim. Vet. Sci. 3(3).

[45] Radostits, OM., Leslie, KE. and Fetrow, J. (1994). Maintenance of reproductive efficiency in dairy cattle. In Herd Health: Food Animal Production Medicine. 2nd ed. Philadelphia: W. B. Saunders Company, 141-158.

[46] Tigre, W. (2004). Major clinical reproductive health problems of dairy cows in and around Holleta. DVM thesis. Addis Ababa University, Debre Zeit, Ethiopia.

[47] Berglund, B., Steinbock, L. and Elvander, M. (2003). Causes of stillbirth and time of death in Swedish Holstein calves examined post mortem. Acta Vet. Scand.44(3): 111-120.

[48] Abuom, TO., Njenga, MJ., Wabacha, JK., Tsuma, VT. and Gitau, GK. (2012). Incidence and risk factors of periparturient conditions in smallholder dairy cattle herds Kikuyu Division of Kiambu District, Kenya. Eth. Vet. J. 16(2): 85-102. 